\title{
Personnel Factors of Corporate Internal Auditing on the Contemporary Microeconomics Environment in the United States
}

Victor W Gaines ${ }^{1}$ and Karina Kasztelnik ${ }^{2}$

ABSTRACT

\begin{abstract}
The purpose of this quantitative, correlational research was to examine to what extent the personnel factors of internal auditing departments predict the control environment within the public sector. Using the 2013 COSO Internal Control-Integrated Framework as the theoretical framework, we addressed the extent to which the internal audit staffing size per engagement, professional development, and auditing experience of auditors predict the overall control environment and each of the five components of COSO. The results of six multiple linear regression models showed no statistically significant with the exception between professional development and Principle 4 Recruitment. A nonparametric Kendall's tau-b correlation analysis revealed a significant relationship between professional development and Principle 4 Recruitment, $\tau_{b}=0.388, p=0.030$. The results of this study may contribute to the positive global economy change by bringing into focus the role of auditing and its positive impact on the worldwide public auditing policy.
\end{abstract}

KEY WORDS: $\quad$ COSO, Government Auditing, Governance, Internal Auditing, Personnel Factors, Control Environment. JEL Classification: H83, M42, M48.

1 Pacific Union College

${ }^{2}$ Grand Canyon University

\section{Introduction}

By using a quantitative correlational method, this study examines whether and to what extent aspects of internal audit personnel can predict the control environment within the public sector. As it pertains to the aspects of internal audit personnel, we used three staffing aspects of internal audit - staffing size per engagement, professional development, and the auditing experience of auditors - as the predictor variables. As it pertains to the overall control environment, the criterion variables consisted of each of the five components of control environment - integrity, independent oversight, providing structure, recruitment, and accountability as identified by the Committee of Sponsoring Organizations of the Treadway Commission (COSO) Internal Control-

Correspondence concerning this article should be addressed to: Karina Kasztelnik, Grand Canyon University.

E-mail: karina.kasztelnik@my.gcu.edu
Integrated Framework (COSO, 2013). As in the global accounting sector, public organizations put a high reliance on their internal control system. To be able to evaluate an internal control system, internal auditors must use a framework to ensure that the controls are working effectively. The COSO Internal Control-Integrated Framework provides a systematic approach to assessing internal control. However, within the components of both of these frameworks, the control environment serves as an umbrella for the other four components: risk assessment, activity controls, information and communication, and monitoring (Noland \& Metrejean, 2013).

According to the COSO (2013) and U.S. Government Accountability Office (2014), an organization's control environment focuses on five concepts. These concepts include: (a) commitment to integrity and ethical values, (b) Independence and oversight, (c) structure, authority, and responsibility, (d) commitment to competence, and (e) accountability (Burns 
\& Simer, 2013). Each of these five components assist in evaluating different aspects of an organization's control environment. However, it is management's responsibility of overseeing a department's control environment (U.S. Government Accountability Office, 2014).

This study has far-reaching implementations, as, an effective and efficient internal audit department can increase the likelihood of identifying deficiencies and focus on the importance of good governance. As an important part of an organization's governance system and internal audit department, an internal audit department can positively reflect on attributes and the behavioral tones of an organization's control environment. Thus, this study emphasizes the importance of the internal audit department as a whole.

Additionally, this study has implementations for the global aspect of the internal audit industry. Because audit departments spend a significant amount of time in the planning stage of an audit, this study can assist chief audit executives in effectively planning their required staff, professional development, and the auditing experience of auditors based upon risk. This would, in turn, assist audit departments in improving their effectiveness.

Because internal control is essential to any organization, the internal audit function plays a significant role in assisting the board in accomplishing their task as it pertains to their governance responsibilities (Florea \& Florea, 2013). In Suyono and Hariyanto's (2012) case study on corporate governance in Indonesia, the researchers examined the relationship between organization commitment, internal audit, and internal control, and the organization's corporate governance. This research identified that internal audit, internal control, and organization commitment have a positive relationship with the organization's corporate governance (see Figure 1).

This commitment toward governance has increased exponentially since the aftermath of Sarbanes-Oxley. The accounting and auditing fields have collaborated to examine practical methods to implement, refine, and improve internal control. Due to this collaboration, the accounting and auditing fields turned to the COSO for a theoretical framework. This theoretical framework would help both industries in evaluating internal control (Janvrin et al., 2012) . Thus, in 1992, the Sponsoring Organizations of the Treadway Commission developed the COSO Internal Control-Integrated Framework to help organizations to improve their control structure. In May of 2013, COSO updated its Internal Control-Integrated Framework to assist organizations in developing a better internal control framework for modern business.

The COSO Internal Control-Integrated Framework was the first attempt by any organization to define internal control and provide a standard for measuring it (D’Aquila, 2013). The Sarbanes-Oxley Act also highlighted the importance of internal control, mentioned in section 404. As noted by D'Aquila (2013), the Securities and Exchange Commission ruled that the 2013 COSO Internal Control-Integrated Framework satisfy the criteria and may be used by management for evaluating internal control and disclosing requirements. Therefore, this ruling emphasized the importance of the 2013 COSO Internal Control-Integrated Framework as a theoretical framework used throughout the corporate world for evaluating an organization's internal control system.

This theoretical framework identified five components of internal control: (a) control environment, (b) risk assessment, (c) control activities, (d) information and communication, and (e) monitoring activities (Wilson et al., 2014). Intended to assist organizations in managing and developing their internal control system, the COSO revision included 17 principles (See Table 1).

\subsection{Comparison of Internal Control Systems}

According to Xiao (2011), there are many organizations incorporate many procedures to enhance their internal control system. For internal auditors, to effectively evaluate an organization's internal control system, there is a need for a framework. This framework allows internal auditors to apply a systematic evaluation to evaluate organizations internal control system. An absence of a framework could lead to a misclassification of the control weakness of an organization's internal system.

As previously mentioned, the 2013 COSO Internal Control-Integrated Framework is a theoretical based 


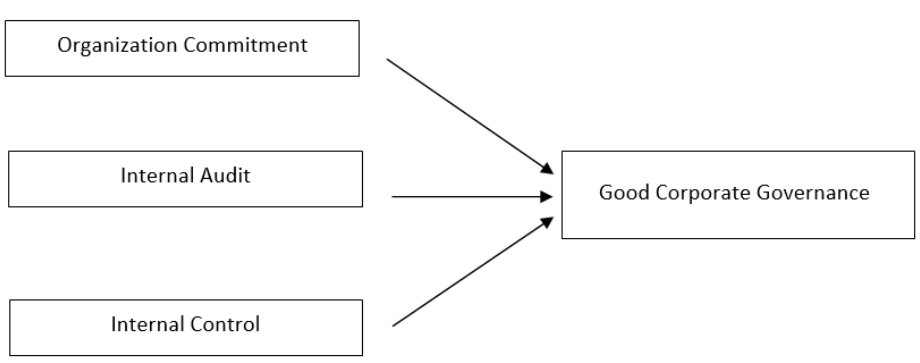

Figure 1. The relationship between organization commitment, internal audit, internal control and good corporate governance.

Note: Adapted from "Relationship Between Internal Control, Internal Audit, and Organization Commitment with Good Governance: Indonesian Case" by (Suyono \& Hariyanto, 2012) China-USA Business Review, 11 (9), pp. 1237-1245. Reprinted with permission.

Table 1. Five Internal Control Components with Their Corresponding Principles

\begin{tabular}{|c|c|c|c|c|}
\hline Control Environment & Risk Management & Control Activities & $\begin{array}{l}\text { Information and } \\
\text { Communication }\end{array}$ & Monitoring Activities \\
\hline $\begin{array}{l}\text { - Commitment to integ- } \\
\text { rity and ethical values }\end{array}$ & $\begin{array}{l}\text { - Specify objectives } \\
\text { clearly }\end{array}$ & $\begin{array}{l}\text { - Selects and } \\
\text { develops control } \\
\text { activities }\end{array}$ & $\begin{array}{l}\text { - Uses relevant } \\
\text { information }\end{array}$ & $\begin{array}{l}\text { - Conducts ongoing } \\
\text { reviews and evaluations }\end{array}$ \\
\hline $\begin{array}{l}\text { - Independence and } \\
\text { oversight responsibility }\end{array}$ & $\begin{array}{l}\text { - Identifies and } \\
\text { analyzes risk }\end{array}$ & $\begin{array}{l}\text { - Selects and } \\
\text { develops control } \\
\text { activities over } \\
\text { technology }\end{array}$ & $\begin{array}{l}\text { - Internal com- } \\
\text { munication }\end{array}$ & $\begin{array}{l}\text { - Evaluate and commu- } \\
\text { nicate internal control } \\
\text { deficiencies }\end{array}$ \\
\hline $\begin{array}{l}\text { - Structure, authority, } \\
\text { and responsibilities } \\
\text { - Commitment toward } \\
\text { competence }\end{array}$ & $\begin{array}{l}\text { - Assesses fraud risk } \\
\text { - Identifies and } \\
\text { utilizes changing to } \\
\text { internal control }\end{array}$ & $\begin{array}{l}\text { - Implement poli- } \\
\text { cies and procedures }\end{array}$ & $\begin{array}{l}\text { - External com- } \\
\text { munication }\end{array}$ & \\
\hline - Accountability & & & & \\
\hline
\end{tabular}

Note: Adapted from “COSO enhances its internal control: Integrated framework," by J. Burns and B. Simer, 2013, DeloitteHeADS Up, 20(17), pp. 1-16. 
framework to assist internal controls in evaluating an organization's internal control system (Wilson et al., 2014). This theoretical framework identified five components of internal control: (a) control environment, (b) risk assessment, (c) control activities, (d) information and communication, and (e) monitoring activities (Wilson et al., 2014). Intended to assist organizations in managing and developing their internal control system, the 2013 COSO Internal Control-Integrated Framework includes 17 principles. These principles provide clarity regarding the role, implementation, and behavior internal control as well as assessing effectiveness (Burns \& Simer, 2013; D'Aquila, 2013).

The control environment component of COSO focuses on the integrity, ethical values, management's philosophy and operating style of the organization. Risk assessment emphasizes the identification and evaluation of the risk that could jeopardize the organization's existence. Control activities are those policies and procedures within the organizations that contribute to the overall controlling aspect of management. Identification and communication focus on the ability of management to communicate effectively to their decision-makers and stockholders. Finally, monitoring emphasizes the continuous assessment of the quality of the control system itself (COSO, 2013; D'Aquila, 2013; Wilson et al., 2014).

As with the global sector, the public sector uses a framework to help them evaluate their internal control system. An example of this would be the 2014 Standards for Internal Control in the Federal Government which provides managers with criteria for designing and implementing an effective internal control system (U.S. Government Accountability Office, 2014). Better known as The Green Book, these standards apply to the US federal government, state and local government entities, along with not-for-profit organizations.

When comparing the COSO Internal ControlIntegrated Framework to the Green Book, one will find some strong similarities. These similarities were because in 2013, the GAO proposed changes to the Standards for Internal Control in the Federal Government to align with the COSO Internal ControlIntegrated Framework to meet the modern challenges faced by the federal government (D'Aquila
\& Houmes, 2014). Therefore, because of the similarities, one may conclude that the Green book and the COSO Internal Control-Integrated Framework are practically identical except for some minor differences within the principles. Thus, COSO Internal Control-Integrated Framework used as out theoretical framework for this study.

\subsection{Control Environment}

The control environment is one of the five components found in both the COSO Internal ControlIntegrated Framework and the Standards for Internal Control in the Federal Government. According to the COSO (2013), the control environment component represents the organization's standards, processes, and structures that provide the basis for the organization's corporate governance. According to Janvrin et al. (2012), the elements of an organization's control environment consist of their integrity and ethical values along with management's philosophy and operational style. These concepts help to set the organization's tone at the top. Spoehr (2012) added that the tone at the top requires the organization to have explicit and implicit policies that align with the organization's objectives and goals. Both of these concepts are essential for an organization's control environment.

In Hermanson et al. (2012) examination of an organization's control environment, the authors found that the perceived strengths of the organization's control environment were higher than what was reported by the chief audit executive to the audit committee. They also added that if an organization's control environment is not strong, this will lead to the undermining of the other components of internal control. This would lead one to believe that an organization's control environment is the foundation of an organization's internal control system.

In Sarens and Abdolmohammadi's (2011) article on the monitoring effects of internal control, the authors examined at the impact of the organization's control environment and its relation to the size of the internal audit function. Their results found that the control environment of an organization has a significant effect on the relative size of the internal audit function. Therefore, when an organization focuses on their control environment, they tend to 
have larger internal audit departments. While the results of this study focused on firms in Belgium, the author suggested that future studies examine larger samples, to include public practices to substantiating their results.

Badara and Saidin's (2013) theorized based, on their literature review, that an effective internal control system can influence the effectiveness of an internal audit department within the public sector. However, the authors stated that this hypothesis needed to be validated empirically. This study attempts to substantiate this theory by examining whether and to what extent aspects of internal audit personnel can predict the control environment within the public sector.

This study has far-reaching implementations, whereas, an effective and efficient internal audit department can increase the likelihood of identifying deficiencies and focus on the importance of good governance. As an important part of an organization's governance system and internal audit department, an internal audit department can positively reflect on attributes and the behavioral tones of an organization's control environment. These results will help provide policymakers information in regards to personal factors that may affect an organization's control environment. Additionally, this new information will help assess auditing departments as it pertains there to their compliance with their guidance and assist in future plantings of audit engagements. Thus, this study can emphasize the importance of the internal audit department as a whole.

Furthermore, this study has implementations for the global aspect of the internal audit industry. Because audit departments spend a significant amount of time in the planning stage of an audit, this study can assist chief audit executives in effectively planning their required staff, professional development, and the auditing experience of auditors based upon risk. This would, in turn, assist audit departments in improving their effectiveness.

\section{Background And Hypotheses}

Due to the recent corporate scandals, corporate governance has become critical to an organization's operations. In recent years, internal auditing has been increasingly critical to organizations as a mechanism for monitoring corporate governance, risk management, and internal control. Therefore, many organizations set up an internal audit department to provide organizational oversight of their internal control system. Internal audit departments also assist organizations by providing recommendations to improve these systems so that these organizations can meet their operational goals.

In providing assistance and oversight, internal audit departments have needed to use a systematic, disciplined approach to performing their assessment in evaluating an organization's internal control structure (The Institute of Internal Auditors, 2013). The COSO has provided guidance in accounting and auditing. In 1992, COSO developed the Internal Control-Integrated Framework, which provides a systematic approach for assessing internal control. In 2013, COSO updated the Internal Control-Integrated Framework to meet the needs of modern business (COSO, 2013).

The new 2013 COSO Internal Control-Integrated Framework control environment consists of five underlying principles. These principles include a commitment to integrity and ethical values, independence and oversight responsibilities, structure, authority and responsibilities, commitment to retaining competency, and accountability. These principles have an impact on the organization's overall system of internal control and reflect the attitudes and actions of the board of directors (COSO, 2013; The Institute of Internal Auditors, 2011). Thus, the control environment of any organization serves as a fundamental foundation of an organization's internal control system and encompasses the other four sections. Critical to an organization control environment is the ethical and behavioral standards, along with how they are communicated and prescribed within an organization (Noland \& Metrejean, 2013). D'Aquila (2013) reiterated that an organization's control environment was the basis for carrying out internal control throughout the organization.

According to D'Aquila and Houmes (2014), this framework also applied to governmental entities at all levels. This emphasis included 
the control environment component of COSO. As with any organization, governments are facing budgetary pressures from both internal and external entities. These pressures can have an adverse impact on the government's efficiency. In addressing these challenges, the GAO proposed changes to their Standards of Internal Control in the Federal Government and enacted these changes in September 2014. These new revisions are designed to bring the standards in line with modern internal control methods and mirror the 2013 COSO Internal Control-Integrated Framework (D’Aquila \& Houmes, 2014). Because of the importance, the control environment has to an organization's internal control system and corporate governance, this study uses the 2013 COSO Internal Control-Integrated Framework as a theoretical framework. Aikins'(2011) study on government internal audits' role in improving financial performance also used this framework as a theoretical framework, as this framework applies to government agencies because of its similarities to the Standards of Internal Control in the Federal Government. These same standards applied to those governments' internal auditing function within U.S. military organizations because these military audit departments fall under the DOD and the Comptroller General of the United States.

Using the same methodology used by Sarens and Abdolmohammadi (2011) in examining the relationship between organizations control environment and the size of the internal audit function, we examined whether and to what extent aspects of internal audit personnel — staffing size per engagement, professional development, and the auditing experience of auditors-can predict the control environment within the public sector. The criterion variables were the overall control environment and its five components as listed:

Principle 1: Integrity: The organization demonstrates a commitment to integrity and ethical values.

Principle 2: Independent oversight: The board of directors demonstrates independence from management and exercises oversight of the development and performance of internal control.
Principle 3: Providing structure: Management establishes, with board oversight, structures, reporting lines, and appropriate authorities and responsibilities in the pursuit of objectives.

Principle 4: Recruitment: The organization demonstrates a commitment to attract, develop, and retain competent individuals in alignment with objectives.

Principle 5: Accountability: The organization holds individuals accountable for their internal control responsibilities in the pursuit of objectives.

Consequentially, in this study, it was possible to use the five principles of an organization control environment as components of the overall control environment scale. Using six multi-linear regression models (one for each of the six criteria: the overall control environment scale and the five principle subscales), we hypothesize the following:

H1: The internal audit staffing size per engagement, professional development, and the auditing experience of auditors are statistically significant predictors of the overall control environment (average of the scores on the five principles) within the public sector.

H2: The internal audit staffing size per engagement, professional development, and the auditing experience of auditors are statistically significant predictors of the implementation of Principle 1, integrity, within the public sector.

H3: The internal audit staffing size per engagement, professional development, and the auditing experience of auditors are statistically significant predictors of the implementation of Principle 2, independent oversight, within the public sector.

H4: The internal audit staffing size per engagement, professional development, and the auditing experience of auditors are statistically significant predictors of the implementation of Principle 3 , providing structure, within the public sector. 
H5: The internal audit staffing size per engagement, professional development, and the auditing experience of auditors are statistically significant predictors of the implementation of Principle 4, recruitment, within the public sector.

H6: The internal audit staffing size per engagement, professional development, and the auditing experience of auditors are statistically significant predictors of the implementation of Principle 5, accountability, within the public sector.

While other research studies analyzed different aspects of COSO, Badara and Saidin (2013) examined the impact and effectiveness internal controls have on the public level. They concluded that there was a need for further empirical research on the relationship between an organization's control environment and its particular internal audit function. For this examination, we were able to derive the following research question.

RQ1: To what extent does the internal audit staffing size per engagement, professional development, and the auditing experience of auditors predict the overall control environment within U.S. military organizations?

\section{Research Design}

To collect the necessary data, we used an electronic online survey instrument. The target population for the study comprised of two public auditing organizations in the United States using a convenience sample method. All participants in the study were anonymous.

\subsection{Description of the Research Design}

Used in this study was a correlational research design. This type of design is appropriate to investigate the relationships between variables without any intervention or manipulation of the independent variable. This study involved no comparison of groups. Sarens and Abdolmohammadi (2011), and Schmidt (2014) used a similar non-experimental correlational design for the purpose of examining relationships among variables. Thus, the most appropriate design for this study was a nonexperimental correlational research design.

\subsection{Sampling Procedures}

To collect quantitative data, we administered an online survey to a convenience sample of public auditors. The target population for this recruitment consisted of two auditing departments: the Naval Audit Service, and the Marine Corps Nonappropriated Fund Audit Service. Both of these departments represent governmental auditing agency within the United States that use the United States Government Auditing Standards (U.S. Government Accountability Office, 2014). Additionally, both of these auditing activities cover diverse geographic regions.

In calculating the sample size needed to analyze the three predictors adequately, the following information were used for the calculation: expected medium effect size, $\mathrm{f} 2=0.15$ (Cohen, 1992); the standard level of statistical significance, alpha $=0.05$; and minimum power 0.80 (preferably 0.95). Therefore, based on this information, a minimum sample size of 77 participants at a minimum power of 0.80 . As previously mentioned, we recruited a convenience sample of volunteer recipients. The sample would include area directors, audit managers, audit supervisors and staff auditors. Because this would be a convenience sample, there may be an inherent risk that the sample may not represent the population, thus, making it difficult to generalize the sample results to the population.

For the purpose of collecting the primary quantitative data, we used an electronic survey application. The questionnaire included components validated instruments for slight modifications for this purpose of the study. We used questions from the Global Internal Audit Common Body of Knowledge (CBOK) to identify demographics and the three-predictor variables - the participants and years of experience and professional development, and the number of employees in the last engagement (The IIA Research Foundation, 2015). The Florida Department of Economic Opportunity 2014 - 2015 Internal Control Questionnaire and Assessment developed by the Bureau of Financial Monitoring and Accountability provided the framework for collecting data on the five criterion subcategories based upon the five subcategories of the control environment. These subcategories include integrity, independent oversight, providing structure, recruiting, and accountability. We use average scores to calculate the overall control environment results using a Likert scale. Based on this precedent set by Sarens and Abdolmohammadi (2011), we were able to approximate the control environment data to be continuous. 
The data for the six criterion variables-the overall control environment and its five categories were collected using the adopted Florida Department of Economic Opportunity 2014-15 Internal Control Questionnaire and Assessment. This instrument used a Likert score for scoring purposes. Using this data, we computed the means to aggregate the data of the five subscales and the overall scale. This allowed us to approximate the data to the interval using the same instrument. This also allowed us to approximate the continuous data and allow us to aggregate the data.

After data collection, we performed an initial examination of the data set to detect any missing data or outliers. All incomplete set of data were discarded from the dataset. After which, we computed the composite variables as a means of the items corresponded to each skill or subscale, along with, performing a reliability analysis for all composite measurements.

The next step involved a compilation of descriptive statistics. For continuous variables, we performed the following statistics: mean, standard deviation, min, max, skewness, and kurtosis. The last two statistics were used to assess the normality of the distribution curve relative to the normal bell shaped curve.

Before performing the multi-linear regression analysis, we check the assumptions associated with this statistic. We considered the following eight assumptions: (a) continuous criterion variable, (b) two or more predictor variables, (c) independence observation, (d) linear relationship between the criterion and each predictor variable, (e) homoscedasticity, (f) no multicollinearity (i.e., no high correlation among predictors), (g) no significant outliers, and (h) approximately normal distribution of residuals (Laerd Statistics, 2013).

The analysis conducted included six multi-regression models. Additionally, we use the stepwise method of entering the predictors into the regression equation. This allowed us to rank the predictors in terms of strength of their impact of each criterion. Each model had the same three predictors (the internal audit staffing size per engagement, professional development, and the auditing experience of auditors). However, each model had different criterion (the control environment overall scale and one each of the five subscales). The results from each model assisted in answering the research question.

\section{Data Analysis and Test of Assumptions}

We used an electronic survey application to collect data for this project. All those that participated in the survey were voluntary. Within the questionnaire, we asked internal auditors for their insight on their clients' control environment. The participants provide answers using 1 (not at all influential) to 5 (extremely influential) Likerttype scale.

The study sample was considerably lower than 77 participants needed to achieve 0.80 power in the plan multilinear regression analysis. This was because after reevaluating the purpose of the study, one of the public auditing departments withdrew from the study. Additional public auditing departments sought for participation; however, they refused to participate due to internal policies.

Although one may view this as a major limitation of this particular study, the survey results are valid and reliable based on the following reasons. First, the sample size composed of 21 participants from one public agency. This represents a $75.6 \%$ response rate. Such a response rate reduces the risk of the sample size not representing the population. Additionally, the organization that did participate must follow the same guidelines of other government organizations as it pertains to control environment. Secondly, of the 21 participants, 18 (86\%) participants were audit managers or above. The participants' distribution by job description was as follows: one chief audit executive, seven audit directors, ten audit managers, and three staff auditors participated in taking the electronic survey (Table 2). This high-level management participation in the study only adds validity to the results. Lastly, the average years of experience of those participated were 19.9 years. Additionally, the average amount of formalized training for the year was 48.62 hours per year (Table 3 ). Thus, one may conclude that the survey respondents were season auditors and had vast experience in the area of internal auditing and internal control.

Prior to performing this descriptive statistical analysis, we performed a Cronbach's alpha analysis to determine how closely the five control environment principles and overall control environment relate to the three subscales variables and each other. Based upon the results of this analysis, the five internal control principles and overall control environment did relate closely to the three subscales variables and each other with scores well above 0.7 (Table 4 ) in the. Thus, the results are reliable. 
Table 2. Distribution of Participants by Job Description

\begin{tabular}{lcc}
\hline Job Description & $\boldsymbol{n}$ & $\%$ \\
\hline Chief audit executive, or equivalent & 1 & 4.8 \\
Director or senior manager & 7 & 33.3 \\
Manager & 10 & 47.6 \\
Staff & 3 & 14.3 \\
Total & 21 & 100.0 \\
\hline
\end{tabular}

Table 3. Participant Experience and Training

\begin{tabular}{lccc}
\hline Description & Minimum & Maximum & M \\
\hline Years of professional experience & 6 & 33 & 19.9 \\
Hours of formalized training (yearly) & 25 & 120 & 48.62 \\
\hline
\end{tabular}

Table 4. Reliability Analysis for the Criterion Scale and Subscales

\begin{tabular}{|c|c|c|}
\hline Description & Cronbach's Alpha & Number of Items \\
\hline Principle 1 Integrity & .842 & 3 \\
\hline Principle 2 Independent oversight & .839 & 3 \\
\hline Principle 3 Providing structure & .745 & 3 \\
\hline Principle 4 Recruitment & .718 & 3 \\
\hline Principle 5 Accountability & .860 & 3 \\
\hline Overall Control Environment & .859 & 5 \\
\hline
\end{tabular}

Table 5. Descriptive Statistics for the Criterion Variables

\begin{tabular}{llllllll}
\hline & $\boldsymbol{M}$ & Mdn & SD & Min & Max & Skewness & Kurtosis \\
\hline Principle 1 Integrity & 3.25 & 3.33 & .68 & 1 & 5 & -.202 & .763 \\
Principle 2 Independent oversight & 3.16 & 3.33 & .76 & 1 & 5 & -.772 & .360 \\
Principle 3 Providing structure & 3.63 & 3.66 & .67 & 2 & 4 & -.022 & -.037 \\
Principle 4 Recruitment & 3.49 & 3.66 & .81 & 2 & 5 & -.622 & 1.165 \\
Principle 5 Accountability & 3.49 & 3.66 & .82 & 1 & 4 & -.302 & -.386 \\
Overall Control Environment & 3.41 & 3.46 & .59 & 1 & 5 & -.849 & 2.687 \\
\hline
\end{tabular}

Note: $N=21$. 
Table 5 and 6 showed the results of the descriptive statistics computed for both the criterion and predictor variables. The mean scores for all five principles and overall score were above 3 (moderate influential). The consistency of the negative skew statistics indicated that all the distributions were platykurtic. However, the values were within the normal range. Two of the kurtosis values were outside the normal \pm 1 range-Principle 4 , recruitment, and the overall control environment-indicating small and moderate violations of normal bell curve distribution for these two criteria.

Table 6 identified that the shape of the distribution for the predictor variables was positively skewed, with except for auditing experience. Professional development showed kurtosis was higher than 3, meaning that the distribution was leptokurtic. The large kurtosis value suggested that the distribution was normal, which represents a limitation to this analysis. This result may be due to the smallness of the sample size.

Before conducting the planned multiple linear regression analysis, we performed a check of the assumptions. The first two assumptions, continuous criterion variable, and two or more predictor variables were satisfied because the criterion variable was continuous and there were more than two predictor variables. To check for the independence of observation, we performed a Durbin-Watson test on the predictor variables. The results of the Durbin-Watson values ranged between 1.26 and 2.14. Thus, the researcher concluded that the assumption of independence of residuals was satisfied (Table 7).

In assessing the multicollinearity, we performed a variance inflation factor (VIF). The results of this analysis showed all three predictor variables were below 10 . Thus, one can conclude there was no problem with collinearity in this particular data set (Table 8).

To check outliers, we conducted a case wise diagnosis to identify $z$-score values of the variables of interest that are outside the \pm 3 standard deviation range. In all cases, the standard deviation range was less than \pm 3 standard deviation range. Thus, no unusual points identified.

In our analysis of homoscedasticity and normal distribution of residuals, we found moderate violations of normality. Additionally, inspection of the standardized residuals versus unstandardized plots indicated consistent heteroscedasticity, which represents a limitation of this analysis. Both of these instances may be the result of the small sample size.
Finally, the level of statistical significance was the standard 0.05 value. Given the smaller than planned sample size, the post hoc power analysis was 0.234 . This indicated the probability of missing a significant effect was $76.6 \%$. At power 0.80 , the analysis could only capture a very large significant effect $\left(f^{2}>0.655\right)$ (Figure 2$)$. This was a major limitation of the study. These represented limitations of the analysis, very likely due to the small sample. Additionally, the post hoc power of the analysis was very low. Despite of these limitations, we analyzed the data as planned, using six multiple linear regression models.

\section{Results}

\subsection{Test of Hypotheses}

\subsubsection{Integrity ( $\mathrm{H1})$}

The results of the study showed that the internal audit staffing size per engagement, professional development, and the auditing experience of auditors as a whole are not statistically significant predictors of the implementation of Principle 1, integrity, within the public sector. As identified in Table 9, the results of the multiple linear regression analysis demonstrated that the three predictor variables (internal audit staffing size per engagement, professional development, and the auditing experience of auditors) explained $23.1 \%$ of the variance in Principle 1, integrity, $\mathrm{R}^{2}=0.231$, Adjusted $\mathrm{R}^{2}=0.095, \mathrm{~F}(3,17)=1.698$, $p>0.05$ (Table 9). The standardized Beta coefficients for this model, indicating the percentage of one standardized unit change in the criterion variable associated with the standardized unit change in each predictor, were not statistically significant (Table 10). Based on the results of the planned multiple linear regression analysis, we concluded that audit staffing size, professional development, and audit experience were not statistically significant predictors of Principle 1, integrity.

\subsubsection{Independent Oversight (H2)}

The results of the study showed that the internal audit staffing size per engagement, professional development, and the auditing experience of auditors are not statistically significant predictors of the implementation of Principle 2, independent oversight, within the public sector. As identified in Table 9, the results of the multiple linear regression analysis demonstrated that the three predictor variables (internal audit staffing size per engagement, professional development, and 
Table 6. Descriptive Statistics for the Predictor Variables

\begin{tabular}{lcccccc}
\hline & $\boldsymbol{M}$ & SD & Min & Max & Skewness & Kurtosis \\
\hline Staffing Size & 10.07 & 9.003 & 3 & 33 & 1.922 & 2.817 \\
Professional Development & 48.62 & 19.737 & 25 & 120 & 2.709 & 8.661 \\
Experience & 19.9 & 7.085 & 6 & 33 & -.216 & .059 \\
\hline
\end{tabular}

Note: $\mathrm{N}=21$.

Table 7. Results of the Test of Independence of Observations

\begin{tabular}{llc}
\hline Criterion Variable & $\begin{array}{c}\text { Durbin-Watson } \\
\text { Average Score (1-5) }\end{array}$ \\
\hline Principle 1 & Integrity & 2.206 \\
Principle 2 & Independent oversight & 2.140 \\
Principle 3 & Providing structure & 1.784 \\
Principle 4 & Recruitment & 2.051 \\
Principle 5 & Accountability & 1.255 \\
Total & & 2.024 \\
\hline
\end{tabular}

Table 8. Results of the Multicollinearity Analysis for the Predictor Variables

\begin{tabular}{lcc}
\hline Model & \multicolumn{2}{c}{ Collinearity Statistics } \\
\cline { 2 - 3 } & \multicolumn{1}{c}{ VIF } \\
\hline (Constant) & .978 & 1.023 \\
Professional Development & .964 & 1.038 \\
Experience & .982 & 1.018 \\
Staffing Size & & \\
\hline
\end{tabular}

Note: $N=21$. Tolerance is defined as $T=1-R^{2}$. Variance Inflation Factor $(V I F)$ is defined as VIF $=1 / T$.

Table 9. Hypotheses Summaries

\begin{tabular}{|c|c|c|c|c|c|c|c|c|c|}
\hline \multirow[t]{2}{*}{ Model } & \multirow[t]{2}{*}{$\boldsymbol{R}$} & \multirow[t]{2}{*}{$R$ Square } & \multirow{2}{*}{$\begin{array}{l}\text { Adjusted } \\
R \text { Square }\end{array}$} & \multirow{2}{*}{$\begin{array}{l}\text { Std. Error of } \\
\text { the Estimate }\end{array}$} & \multirow{2}{*}{$\begin{array}{c}R \text { Square } \\
\text { Change }\end{array}$} & \multicolumn{3}{|c|}{ Changes Statistics } & \multirow{2}{*}{$\frac{\text { Durbin-Watson }}{\text { Sig. } F \text { Change }}$} \\
\hline & & & & & & FChange & $d f 1$ & $d f 2$ & \\
\hline 1 & 0.275 & 0.076 & -0.880 & 0.625 & 0.076 & 0.463 & 3 & 17 & 0.712 \\
\hline 2 & 0.480 & 0.231 & 0.095 & 0.641 & 0.231 & 1.698 & 3 & 17 & 0.205 \\
\hline 3 & 0.333 & 0.111 & -0.056 & 0.798 & 0.111 & 0.665 & 3 & 17 & 0.586 \\
\hline 4 & 0.186 & 0.035 & -0.136 & 0.710 & 0.035 & 0.203 & 3 & 17 & 0.893 \\
\hline 5 & 0.498 & 0.248 & 0.116 & 0.759 & 0.248 & 1.871 & 3 & 17 & 0.173 \\
\hline 6 & 0.140 & 0.020 & -0.153 & 0.881 & 0.020 & 0.113 & 3 & 17 & 0.951 \\
\hline
\end{tabular}


the auditing experience of auditors) explained $11.1 \%$ of the variance in Principle 2, independent oversight, $\mathrm{R}^{2}$ $=0.111$, Adjusted $\mathrm{R}^{2}=-0.056, \mathrm{~F}(3,17)=0.665, \mathrm{p}>0.05$ (Table 10). The standardized Beta coefficients for this model, indicating the percentage of one standardized unit change in the criterion variable associated with the standardized unit change in each predictor, were not statistically significant (Table 10). Based on the results of the planned multiple linear regression analysis, we concluded that audit staffing size, professional development, and audit experience were not statistically significant predictors of Principle 2, independent oversight.

\subsubsection{Providing Structure (H3)}

The results of the study showed that the internal audit staffing size per engagement, professional development, and the auditing experience of auditors as a whole are not statistically significant predictors of the implementation of Principle 3, providing structured, within the public sector. As identified in Table 190, the results of the multiple linear regression analysis showed that the three predictor variables (internal audit staffing size per engagement, professional development, and the auditing experience of auditors) explained 3.5\% of the variance in Principle 3, providing structure, $\mathrm{R}^{2}=$ 0.035 , Adjusted $\mathrm{R}^{2}=-0.136, \mathrm{~F}(3,17)=0.203, \mathrm{p}>0.05$ (Table 10). The standardized Beta coefficients for this model, indicating the percentage of one standardized unit change in the criterion variable associated with the standardized unit change in each predictor, were not statistically significant (Table 10). Based on the results of the planned multiple linear regression analysis, we concluded that audit staffing size, professional development, and audit experience were not statistically significant predictors of Principle 3, provide structure.

\subsubsection{Recruitment (H4)}

The results of the study showed that the internal audit staffing size per engagement, professional development, and the auditing experience of auditors as a whole are not statistically significant predictors of the implementation of Principle 4, recruitment, within the public sector. As identified in Table 9, the results of the multiple linear regression analysis demonstrate that the three predictor variables (internal audit staffing size per engagement, professional development, and the auditing experience of auditors) explained $24.8 \%$ of the vari- ance in Principle 4, recruitment, $\mathrm{R}^{2}=0.248$, Adjusted $\mathrm{R}^{2}=0.116, \mathrm{~F}(3,17)=1.871, \mathrm{p}>0.05$ (Table 10). The standardized Beta coefficients for this model, indicating the percentage of one standardized unit change in the criterion variable associated with the standardized unit change in each predictor, were not statistically significant except for professional training which had a significance level of .046 (Table 10). However, the internal audit staffing size per engagement, professional development, and the auditing experience of auditors are not statistically significant predictors of the implementation of Principle 4, recruitment, within the public sector as a whole. Based on the results, we concluded that audit staffing size, professional development, and audit experience were not statistically significant predictors of Principle 4, recruitment.

\subsubsection{Accountability (H5)}

The results of the study showed that the internal audit staffing size per engagement, professional development, and the auditing experience of auditors as a whole are not statistically significant predictors of the implementation of Principle 5, accountability, within the public sector. As identified in Table 10, the results of the multiple linear regression analysis demonstrate that the three predictor variables (internal audit staffing size per engagement, professional development, and the auditing experience of auditors) explained $2 \%$ of the variance in Principle 5, accountability, $\mathrm{R}^{2}=$ 0.020 , Adjusted $\mathrm{R}^{2}=-0.153, \mathrm{~F}(3,17)=0.113, \mathrm{p}>0.05$ (Table 10). The standardized Beta coefficients for this model, indicating the percentage of one standardized unit change in the criterion variable associated with the standardized unit change in each predictor, were not statistically significant (Table 11). Based on the results of the planned multiple linear regression analysis, we concluded that audit staffing size, professional development, and audit experience were not statistically significant predictors of Principle 5, accountability.

\subsection{Additional Analyses}

\subsubsection{Substantive Testwork}

Due to the low power in the multiple linear regression analysis, the assumption violations, and the absence of any statistical significance small to large effects, thus making the above findings inconclusive, we performed 
Table 10. Coefficients Analysis

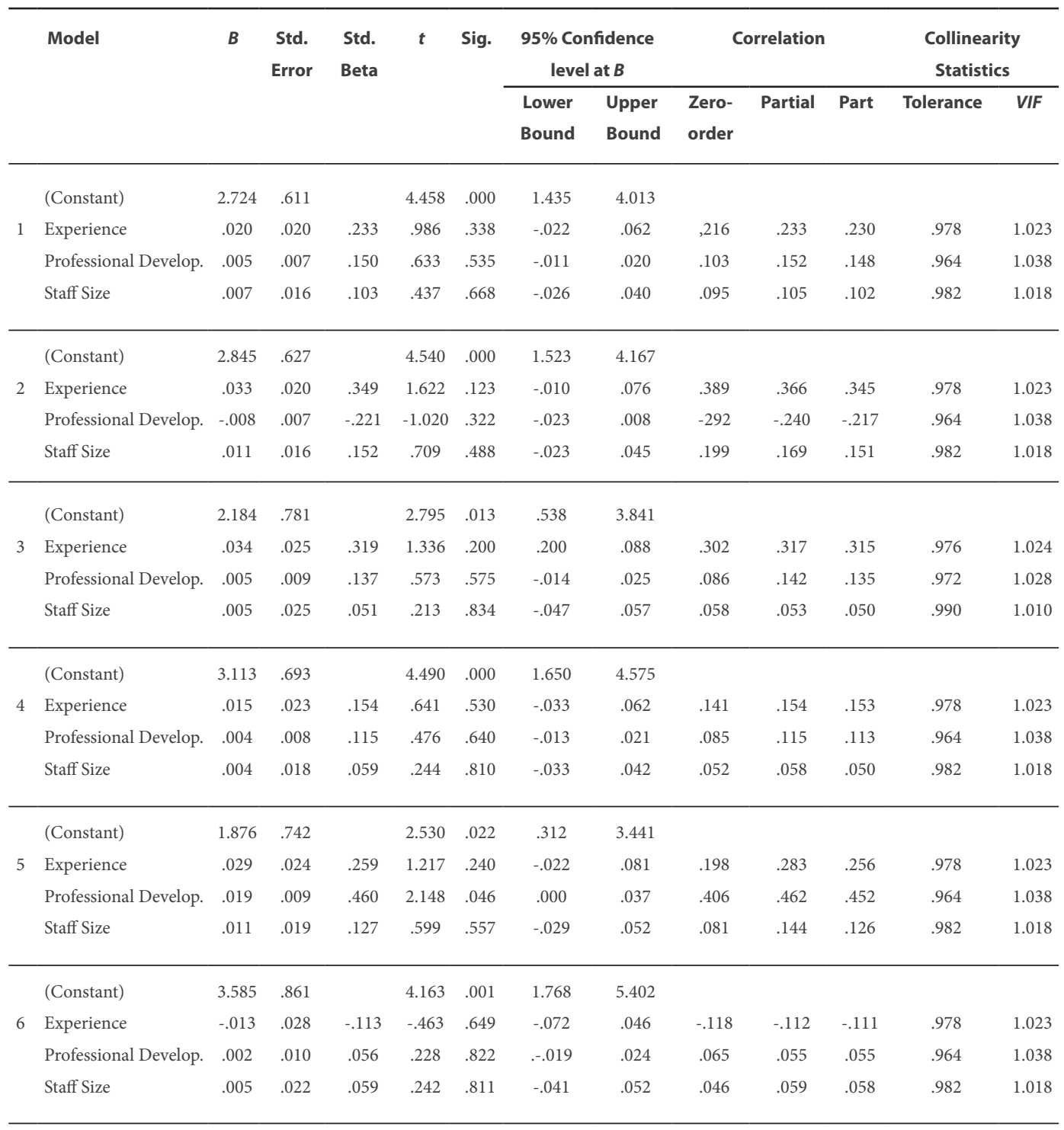

an alternative analysis using the nonparametric Kendall's tau-b correlations (Table 11). The results of this alternative analysis revealed a statistically significant positive correlation between professional development and principle four, recruitment, $\tau_{b}=0.388, p=0.030$. This corroborates with the results identifies with Recruitment (H4) testing.

\section{Discussion}

\subsection{Theoretical and Practical Implications}

The results of the study, based upon descriptive statistics, indicated that each principle was moderately influential to the internal auditor. However, the multiple linear regression analysis indicated that the per- 
sonal factors reviewed did not impact the organization's control environment within the public sector except for a positive correlation between professional development and Principle 4, recruitment. Due to the smaller sample size, further research would be needed to validate this conclusion. Even so, this potential correlation does theoretically identify the importance of an organization's control environment to the internal audit function.

Although there were no significant correlations identified using the multi-linear regression analysis as a whole, Kendall's tau-b analysis in the multiple linear regression analysis identified a positive correlation between professional development and Principle 4, recruitment. The practical implementation suggests that chief audit executives' need to pay closer attention to their internal team's professional development as it pertains to the overall recruiting practices. However, additional research would be needed to validate this conclusion between professional development and Principle 4, recruitment, with larger sample size.

\subsection{Conclusions}

In this quantitative correlational research study, we were unable to identify any correlation between three aspects of internal audit personnel and an organization control environment within the public sector using multiple linear regression analysis. Thus, the internal audit staffing size per engagement, professional development, and the auditing experience of auditors do not predict the overall control environment within U.S. military organizations. However, this study did identify a significant statistical correlation between professional development and Principle 4, recruitment. Additionally, using a nonparametric Kendall's tau-b correlations analysis, we able to find revealed a positive correlation between professional development and Principle 4, recruitment, $\tau_{b}=0.388, p=$ 0.030 . While the sample size was relatively small, both these results indicate a possible relationship between professional development and Principle 4, recruitment. Thus, future research would be needed in this area to validate the magnitude of this relationship in the hopes to be able to shine the light on how potential development may impact recruitment in the area of an organization's control environment.

Table 11. Kendall's Tau-b Correlation Analysis

\begin{tabular}{lcccc}
\hline & & Experience & $\begin{array}{c}\text { Professional } \\
\text { Development }\end{array}$ & Staffing Size \\
\hline Integrity (H1) & Correl. Coefficient & .296 & -.025 & -.025 \\
& Sig. (2-Tailed) & .084 & .892 & .892 \\
& $N$ & 21 & 21 & 21 \\
\hline Independent Oversight (H2) & Correl. Coefficient & .288 & .058 & .058 \\
& Sig. (2-Tailed) & .092 & .750 & .750 \\
\hline Providing structure (H3) & $N$ & 21 & 21 & 21 \\
\hline Recruitment (H4) & Correl. Coefficient & .068 & .103 &. .074 \\
& Sig. (2-Tailed) & .686 & .568 & 21 \\
\hline Accountability (H5) & $N$ & 21 & 21 & -.062 \\
& Correl. Coefficient & .197 & $.388^{*}$ & .711 \\
& Sig. (2-Tailed) & .241 & .030 & 21 \\
\hline Orerall Control & $N$ & 21 & 21 & -.052 \\
& Correl. Coefficient & -.083 & -.156 & .757 \\
& Sig. (2-Tailed) & .621 & .385 & 21 \\
\hline & $N$ & 21 & 21 & -.065 \\
& Correl. Coefficient & .214 & .144 & .691 \\
\hline
\end{tabular}




\subsection{Recommendation for the Future Study}

In identifying future study topics, one must understand the importance of internal control as it relates to an organization's control environment. While the results of the study did identify the positive correlation between professional development and Principle 4, recruitment, further research would be needed to validate the results with a larger population and sample size. The study did identify the importance, public auditors are to the organization's control environment; future research is needed to instantiate these results. Additionally, these recommendations will highlight the potential importance of the internal audit departments as they relate to an organization's governance system.

Finally, one may examine an organization control environment as it pertains to the organization itself. Although it is important for an internal audit department to have a key understanding of the organization's control environment, it is also essential for management to have the same understanding. Therefore, management may use this information to pay closer attention to their control environment as a means to incorporate their governance strategy.

\section{References}

Aikins, S. K. (2011). An examination of government internal audits' role in improving financial performance. Public Finance \& Management, 11(4), 306-337.

Badara, \& Saidin. (2013). Impact of the effective internal control system on the internal audit effectiveness at local government level. Journal of Social and Development Sciences, 4(1), 16-23. https://doi. org/10.22610/jsds.v4i1.731

Burns, J., \& Simer, B. (2013). COSO enhances its internal control - Integrated framework. Deloitte - HeADS Up, 20(17), 1-16.

Cohen, J. (1992). A power primer. Psychological Bulletin, 112(1), 155-159. https://doi.org/10.1037/00332909.112.1.155

Committee of Sponsoring Organizations of the Treadway Commission (COSO). (2013). Internal Control --Integrated Framework. Internal Control over external financial overreporting: A compendium of approaches in examples. COSO.D’Aquila, J. (2013). COSO's Internal Control --Integrated Framework. CPA Journal, 83(10), 22-29.

D’Aquila, J., \& Houmes, R. (2014). COSO’s updated internal control and risk management frameworks. CPA Journal, 84(5), 54-59.
Florea, R., \& Florea, R. (2013). Internal audit and corporate governance. Economy Transdisciplinarity Cognition, 16(1), 79-83.

Hermanson, D. R., Smith, J. L., \& Stephens, N. M. (2012). How effective are organizations' Internal Controls? Insights into specific internal control elements. Current Issues in Auditing, 6(1), A31-A50. https://doi.org/10.2308/ciia-50146

Janvrin, D. J., Payne, E. A., Byrnes, P., Schneider, G. P., \& Curtis, M. B. (2012). The updated COSO Internal Control- Integrated Framework: Recommendations and opportunities for further research. Journal of Information Systems, 26(2), 189213. https://doi.org/10.2308/isys-50255

Laerd Statistics. (2013). Multiple Regression Analysis using SPSS Statistics. https://statistics.laerd.com/ spss-tutorials/multiple-regression-using-spssstatistics.php.

Noland, T. G., \& Metrejean, E. (2013). The importance of the control environment: Expense account fraud at blue grass airport. Journal of Business \& Economics Research (Online), 11(2), 97. https://doi. org/10.19030/jber.v11i2.7622

Sarens, G., \& Abdolmohammadi, M. J. (2011). Monitoring effects of the internal audit function: Agency theory versus other explanatory variables. International Journal of Auditing, 15(1), 1-20. https://doi.org/10.1111/j.1099-1123.2010.00419.x

Spoehr, W. D. (2012). Consequences of this connects of 'tone at the top' at the institutional and operational level. Financial Executive, 28(10), 68-69.

Suyono, E., \& Hariyanto, E. (2012). Relationship between internal control, internal audit, and organization commitment with good governance: Indonesian case. China - USA Business Review, 11(9).

The IIA Research Foundation. (2015). 2015 Global internal audit common body of knowledge (CBOK) practitioner study. https://na.theiia.org/iiarf/Pages/ Common-Body-of-Knowledge-CBOK.aspx

U.S. Government Accountability Office. (2014). Standards for internal control in the federal government: (GAO Publication No. GAO-14$704 \mathrm{G})$.

Wilson, T., Wells, S., Little, H., \& Ross, M. (2014). A history of internal control: From then to now. Academy of Business Journal, 1, 73-89.

Xiao, Q. (2011). Research on the status of SMEs of Yaan in the internal control. Journal of Management and Strategy, 2(3), 86-90. 